\title{
Corrigendum
}

\section{Corrigendum to "Biodegradation of PAHs by Burkholderia sp. VITRSB1 Isolated from Marine Sediments"}

\author{
T. Revathy, M. A. Jayasri, and K. Suthindhiran \\ Marine Biotechnology and Bioproducts Laboratory, School of Biosciences and Technology, VIT University, Vellore, \\ Tamil Nadu 632014, India \\ Correspondence should be addressed to K. Suthindhiran; ksuthindhiran@vit.ac.in
}

Received 11 July 2019; Accepted 16 July 2019; Published 4 December 2019

Copyright (c) 2019 T. Revathy et al. This is an open access article distributed under the Creative Commons Attribution License, which permits unrestricted use, distribution, and reproduction in any medium, provided the original work is properly cited.

\begin{abstract}
In the article titled "Biodegradation of PAHs by Burkholderia sp. VITRSB1 Isolated from Marine Sediments" [1], there is an error in the Results and Discussion section where the text reading "PAHs are group of compounds composed of fused aromatic rings that are highly stable and carcinogenic" should be corrected to "Some PAH compounds and their metabolites are highly stable and carcinogenic."
\end{abstract}

\section{References}

[1] T. Revathy, M. A. Jayasri, and K. Suthindhiran, "Biodegradation of PAHs by Burkholderia sp. VITRSB1 isolated from marine sediments," Scientifica, vol. 2015, Article ID 867586, 9 pages, 2015. 


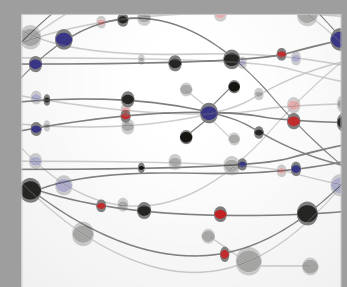

The Scientific World Journal
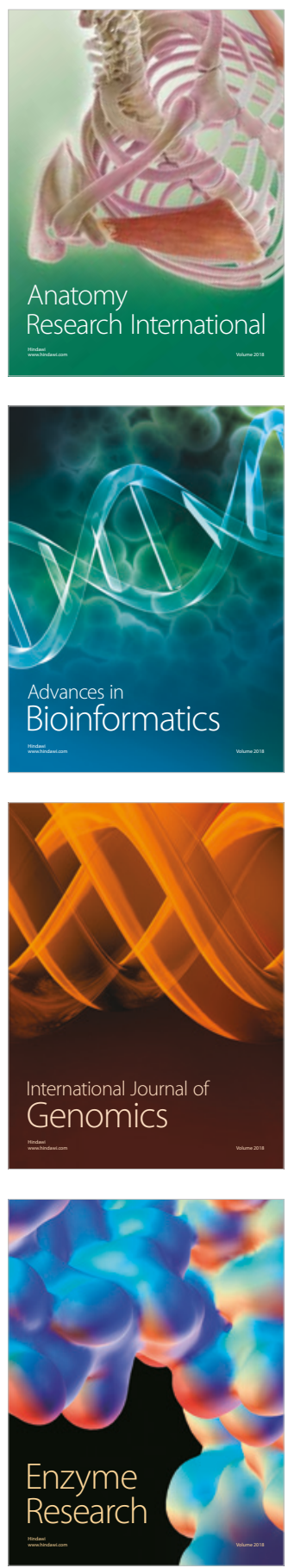
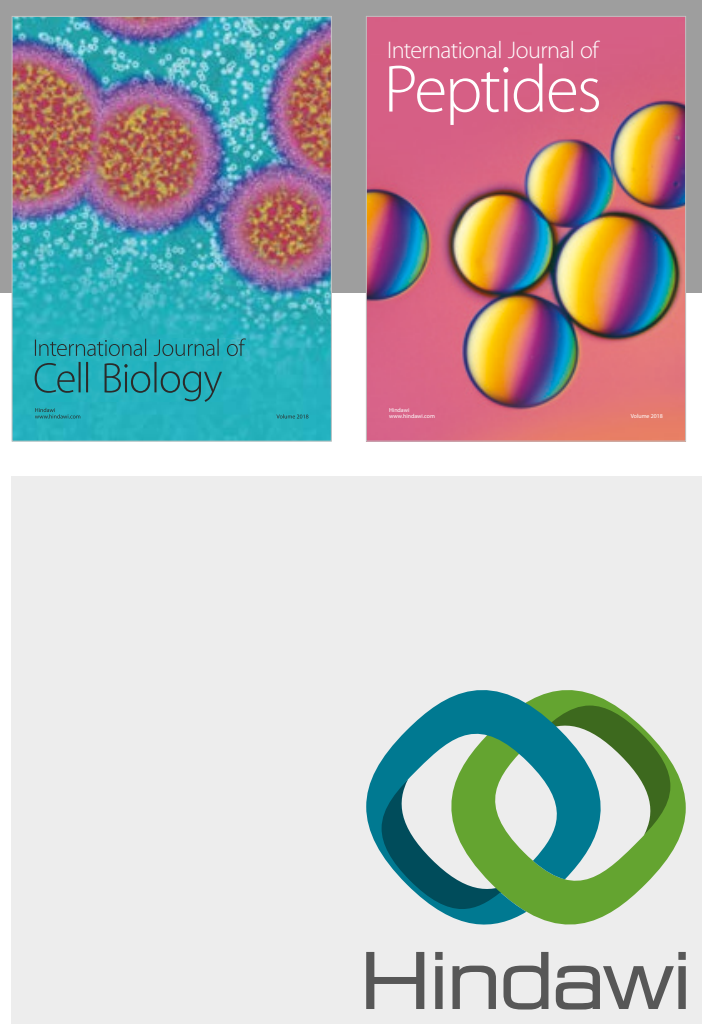

Submit your manuscripts at

www.hindawi.com
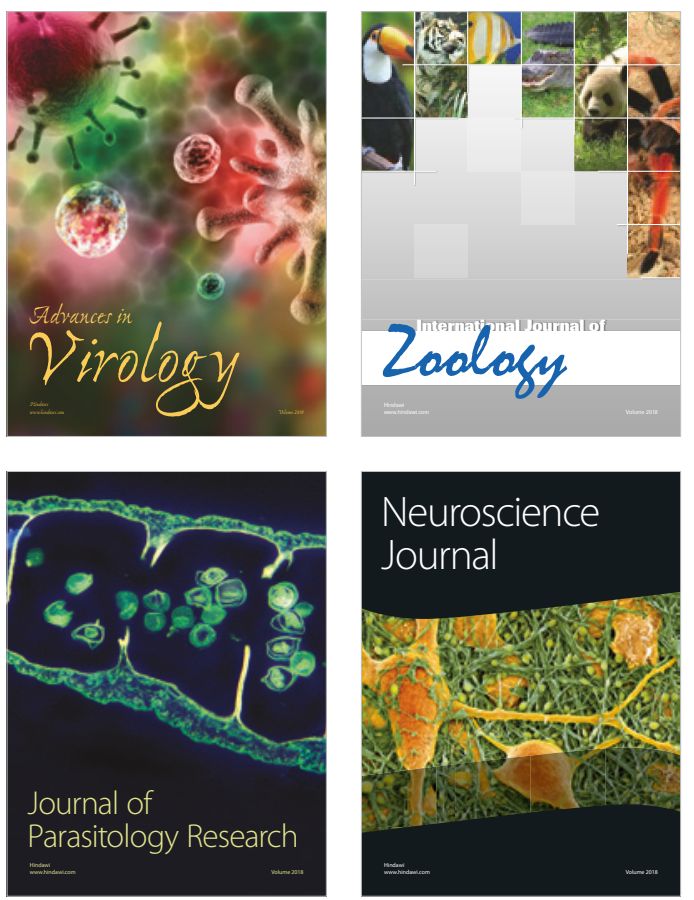
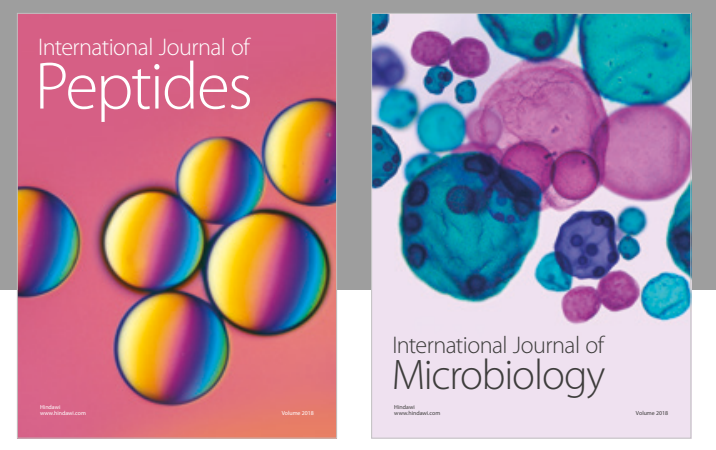

nternational Journal of Microbiology
Journal of
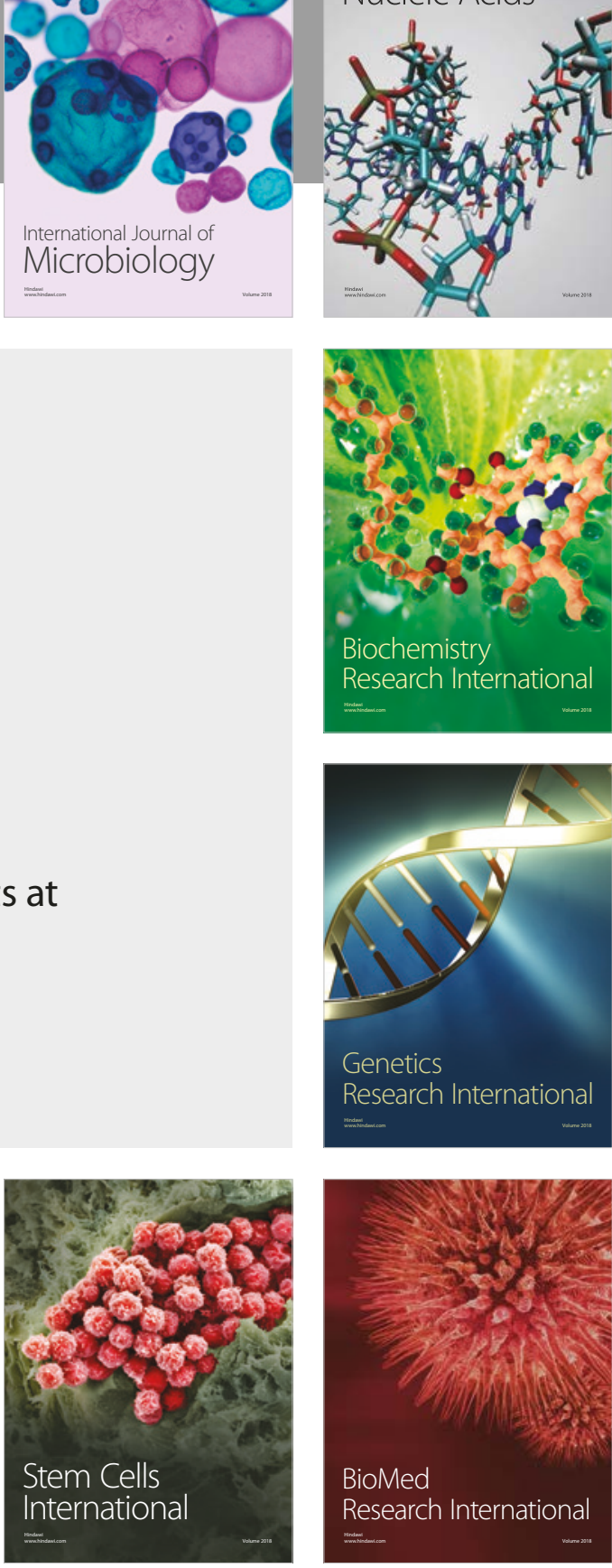
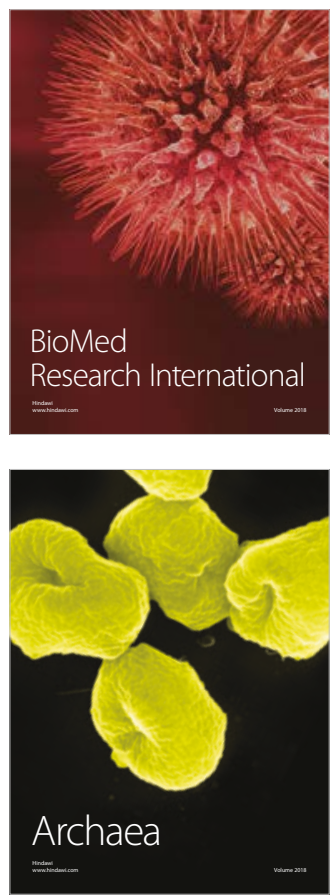